\title{
Sexualidade e saúde
} emocional

\author{
Amparo Caridade*
}

"Com o prazer a vida é uma aventura criativa; sem ele é uma luta pela sobrevivência ".

\section{A. Lowen}

A psicanálise coloca na base do sofrimento psíquico e emocional, a questão da insatisfação, sobretudo a insatisfação sexual. Isso nos remete à compreensão de que o prazer tem um lugar especial na construção do bem estar humano, em nossa saúde emocional. Esse bem estar não resulta apenas de prazeres conquistados, mas da forma como acolhemos a vida em sua totalidade, em suas dimensões prazerosas e sofridas, em sua agonia e seus êxtases. Nesse texto analiso o "ser só", "ser separado", como a condição mais natural de nossa realidade. A partir dela é que somos provocados para o exercício do encontro com alguém e isso mitigará nossa agonia de nos sentirmos carentes e incompletos. Dessa forma o amor é destacado como busca inquieta, como algo que nos falta, longe da plenitude portanto. Por

\footnotetext{
* Psicóloga: Membro da Comissão de Qualificação da SBRASH.
} 
fim enfoco a sexualidade como um dos componentes da saúde emocional das pessoas.

\section{O AMOR, A FALTA E A ANGUSTIA DE SER SÓ}

Das falas acerca do amor, a do Banquete, de Platão (95), parece das mais completas. Dos sete discursos ali mantidos, destaco dois momentos importantes para esta reflexão. O primeiro é quando Aristófanes narra o mito da origem e nos oferece a imagem do andrógino como um ser completo, feliz talvez. Explicava ele que nossa natureza na origem era diferente, ou seja: nossos ancestrais eram duplos, esféricos, tinham órgãos duplos. A dualidade genital explica que havia três gêneros na espécie humana; os machos, as fêmeas e os andróginos, que tinham ambos os sexos. Todos tinham força e bravura excepcionais e tentaram escalar o céu para combater os deuses. Zeus indignado com tal ousadia resolveu puní-los cortando-os ao meio. Acabava a completude, a unidade, a felicidade. A partir daí cada um é obrigado a buscar sua outra metade. Esse mito nutriu em nossa cultura, a ilusão da grande e definitiva completude. O sonho de Aristófanes nos libertaria talvez da solidão, nos enviaria a um amor total, à união perfeita, à idéia de que poderemos ser "felizes para sempre", ou "até que a morte nos separe", ou ao sonho da Cinderela encontrando o príncipe encantado.

Sponville (96) comentado esse mito afasta de nossos sonhos a idéia existente de lima união perfeita, idealizada pelo "encontro da outra metade". Lembra ele que nada mais improvável e nada mais contrário à nossa experiência cotidiana do que "esses dois seres que formam um só". mostra inclusive que é preciso ser dois para fazer amor, razão porque o coito, ao invés de abolir a solidão, a confirma, isso porque, depois do amor, voltamos à condição de separados. "Eles queriam ser um só e ei-los mais dois que nunca" (Sponville, 96). Nesse ciclo podemos escapar da tristeza pelo maravilhamento do prazer, do amor, do encontro. Sponville nos alerta porém, que o amor, o encontro, supõe a dualidade, não a fusão dos seres ou a abolição das diferenças.

O segundo momento é quando Sócrates, para falar do amor, invoca Diotima e ela diz que o amor não é Deus, nem um deus, mas amor a alguma coisa que desejamos e que nos falta. O amor é revelado não como completude, mas como incompletude, não é fusão, mas busca, não é perfeição plena, mas pobreza devoradora. O amor é desejo, e desejo é falta, o amor "ama aquilo que lhe falta e que não possui", diz Platão (95). O que não 
somos, o que não temos, isso é que é objeto de desejo e de amor. A imagem que Diotima faz do amor é a de que ele "é sempre pobre, sem sapatos, sem domicílio, inquieto, sempre na pista do que é bom e belo, sempre caçando, inquieto, ardente, cheio de recursos, esfaimado, ávido". A própria imagem da falta. Imagem que nos distancia muito da idéia de completude posta no mito por Aristófanes.

Como poderíamos então escapar dessa carência, dessa pobreza revelada por Diotima? O amor não escapa da falta, da miséria, da infelicidade, a não ser parindo, diz Platão (95). Uns parem segundo o corpo, solução mais fácil e mais natural, outros segundo o espírito, criando, produzindo arte, ciência, como uma possível solução para a condição faltante do amor. A proposta criadora vai se tornando mais exigente e Platão fala do parto da beleza: amar primeiro um só corpo por sua beleza, depois todos os corpos belos, depois a beleza das almas que é superior à dos corpos, depois a beleza das leis, das ciências, enfim a Beleza absoluta, o Belo em si. "É aonde nos conduz o amor, é o que o salva e nos salva", diz Diotima. Ou seja, o amor posto para fora de si mesmo, num êxtase de si no outro, deixa de ser egoísmo, ausência, vazio.

A partir da idéia do ser dois e não um, até mesmo no ato amoroso, podemos refletir que há na base do ser humano uma angústia de ser separado. Angústia da qual nos reconfortamos na fusão amorosa/sexual. Mas, como um ciclo, depois do amor, nos deparamos de novo com o vazio de ser só. Ser só não é nossa perdição, é nossa condição humana. Encarada, acolhida essa angústia, essa inerência sofrida, ela é posta a serviço da vida. É aí o lugar do aprofundamento do ser, é daí que se pode partir maior, mais si mesmo para a partilha amorosa com outra pessoa.

\section{A BUSCA DA SATISFAÇÃO COMO CAMINHO DE BEM ESTAR}

O prazer da unidade amorosa é provisório. Mesmo assim ele nos resgata. $\mathrm{O}$ ato amoroso sexual torna-se uma espécie de repouso desse ser só, um resgate provisório de nosso sonho mítico de inteireza. Parece ser este o papel essencial do prazer sexual na experiência humana: o de oxigenar nossa solidão, o de embasar o bem estar, a saúde emocional da pessoa. A experiência de amar e sentir-se amada, pode ser vivida como a mais completa sensação de saúde. Em geral a pessoa feliz é também saudável. 
Um grau de satisfação básica na experiência humana é necessário, é estruturante da auto-estima do sujeito, de sua capacidade de amar e ser amado. Por isso o homem busca, se dirige, anseia, pensa deseja e sonha. Uma espécie de tropismo o move nessas direções prazenteiras do existir. $\mathrm{O}$ organismo é impelido a encontrar algum objeto que satisfaça, pelo menos parcialmente, essa busca. A sexualidade enquanto um caminho de prazer, e fonte natural de satisfações, pode atender parte dessa demanda. Jamais completamente, porque a experiência de satisfação inclui sempre uma falta. Ela é também a experiência de um vazio no sentido de que nunca se completa. Essa é uma característica própria da sexualidade humana. Paradoxalmente buscamos algo que sabemos, jamais será pleno.

A sexualidade não é o único caminho de prazer, a única fonte de satisfação. É a mais forte, a mais imperiosa e concreta possibilidade prazerosa, mas não a única. Sem dúvida o prazer orgástico impõe-se como a maior referência prazerosa. Contudo a possibilidade humana de gozo é quase infinita. Há uma gama incomensurável de possibilidades prazerosas que se aninha na teia de relações que estabelecemos conosco mesmos, com os outros, com as coisas, com a natureza, com o mundo. Neste sentido o prazer orgástico pode polarizar a pluralidade de prazeres que a vida possibilita, como uma grande síntese.

\section{AS MARCAS DO TEMPO E DA CULTURA SOBRE A LIBIDO}

"O mal estar básico do final desse milênio está na queda da libido", anunciava Ivan Corrêa, no Encontro do Centro de Estudos Freudianos em Recife, 97. Parece paradoxal essa afirmação num tempo de tanta "liberação sexual". Como declinará a libido se ela é tão estimulada hoje em dia? Talvez devamos nos perguntar, que liberação se dá de fato? Na verdade, o que está sendo liberado não é a libido em sua vertente erógena, mas o consumo sexual. A dimensão erógena do sujeito faz parte de sua internalidade. Isso a diferencia em muito do consumo sexual.

A vida na sociedade pós-moderna tem se apresentado como uma imensa acumulação de espetáculos, como uma inversão concreta da vida. Esse é o modelo atual da vida dominante na sociedade. Guy Debord (97) analisando a Sociedade do Espetáculo mostra o social mergulhado no êxtase das encenações. Este espetáculo é o de uma sociedade em que a vida real é pobre e fragmentária e os indivíduos são obrigados a contemplar e a consumir passivamente as imagens de tudo o que lhes falta. Esse espetácu- 
lo mediado pelas imagens, é a afirmação da aparência e a afirmação da vida humana como simples aparência. Nesse contexto de encenações, a sexualidade também circula em palavras e imagens como a mais universal das mercadorias.

A aparência que é própria da Sociedade do Espetáculo assume ares de positividade, obedecendo à lógica de que "o que aparece é bom, e o que é bom aparece". Mas, o que aparece? Mostra-se o banal, o efêmero, o consolo infantil do consumo, o fascínio e o monopólio da mercadoria. Debord fala da degradação que sofreu a realização humana, e mostra o sucessivo deslizamento que ocorreu, do SER para o TER, e agora, para o PARECER. Nessa conjuntura é importante parecer ser feliz, parecer ser rico, potente ou sociável. É o espetáculo como avesso do valor vivido, o pseudo uso da vida, o pseudo gozo do mundo. O consumo torna-se uma espécie de religião diante da liberdade soberana da mercadoria e o consumidor torna-se um consumidor de ilusões.

Nesse contexto do faz de conta, não estará a libido sendo mais impedida do que liberada? A libido encerra dimensões de busca do prazer que escapam à parafernália midiática do que é dito ou mostrado acerca do sexo. A libido é busca sim do prazer de ver, de ouvir, de consumir, mas também o prazer que é de outra ordem, que é capacidade de gozo, que a caracteriza como erótica. E o que é erótico está na internalidade do sujeito. "Erótica é a alma", diz Adélia Prado (91). Erótica é a linguagem diria Santaella, "a que percorre, como um tremor na espinha, os tecidos subcutâneos da escritura" (in Chalhub, 93). É essa alma erótica que possibilita o gozo.

A alma porém é negada no processo de banalização discursiva, no espetáculo do sexo, na imposição voyeur de nossa cultura consumista. $\mathrm{O}$ corpo é consumido como se consome coisas. A busca de coisas para ser consumidas ilude nosso vazio do prazer não satisfeito. Nenhum mal existe no prazer que é extraído das coisas, mas no estancar nelas enquanto ilusão de preenchimento. Há uma ânsia de consumir, de preencher, e torna-se mais fácil consumir as coisas. A. Jabor diz que há uma felicidade nas coisas, que elas são compráveis, comparáveis, e acima de tudo as coisas não sofrem, diz ele. Coisificamos também o corpo do outro, talvez para consumí-lo sem o sofrimento dos enroscamentos afetivo/amorosos. Talvez esses sejam alguns dos males emocionais com os quais nos deparamos nesse fim de milênio: o sacrifício da alma que é erótica, o sacrifício do afeto, o medo do envolvimento, a prevalência do desempenho sobre a emoção.

Qual será o efeito desse sexo desnudado, encenado, destituído do afeto e de seu mistério? Qual será o destino do afeto banido do sexo, das 
relações? Joyce McDougall (87) diz que todo afeto suprimido do psiquismo, tende a retornar em forma de sintoma. De certo, serão sintomas que se erguem como barreiras ao prazer, à felicidade, que afetam nosso bem estar emocional. Falando das representações coletivas da sexualidade como os Sex-shops, a pornografia, Joyce aponta para um sintoma social. Diz ela: "Talvez exista aí um efeito de aplainamento: as pessoas não inventam mais as suas próprias fantasias masturbatórias, elas as compram. A falta de imaginação pode tornar-se, um dia, um sintoma neurótico" (idem). Esse aplainamento, é a tentativa de apagamento da singularidade, da experiência como coisa única, como alcance do ser.

\section{A SEXUALIDADE E A SAÚDE EMOCIONAL}

A sexualidade desliza de sua dimensão instintual para a representação, salta do instinto à pulsão. Torna-se o lugar enigmático em que o homem e o animal, a Natureza e a natureza humana encontram-se. Por isso ela é muito intensa e duradoura no imaginário onde ela transpõe o concreto. $\mathrm{Na}$ alma erótica, na poética, na arte, ela faz-se eco, ressoa no espírito, como uma boa gargalhada, alimentando o bem estar do indivíduo, promovendo saúde emocional.

A sensação de saúde é uma sensação de inteireza, de harmonia, de bem estar, de vitalidade e de prazer com o corpo, com a vida e com as relações. Em sua etmologia, a palavra saúde quer dizer "integral". A saúde reune então aspectos do corpo, do imaginário, do social, do psíquico, do espiritual. Reflete-se na vitalidade do corpo, no gosto de si, no gozo de viver, no brilho dos olhos, na soltura da expressão, na graciosidade dos movimentos, na sexualidade expressiva e prazenteira.

Não penso que apenas os estados de satisfação promovem saúde emocional, mas a integração das diversas dimensões que constituem cara e coroa do viver. Olhar a vida como possibilidade de gozo e dor, de agonia e êxtase, de vazio e plenitude é sinal de equilíbrio. Viver é uma busca de equilíbrio no desequilíbrio. O êxtase não seria tão encantador se não conhecessemos a agonia; o encontro não seria tão fecundo sem a experiência da solidão. Numa dinâmica da possibilidade/impossibilidade a gente se mantém no fio da sabedoria trágica, inventando formas mais econômicas de lidar a cada instante com o que somos e o que não somos, com o que temos e o que não temos, com o que gozamos e o que doemos. 
"A sanidade mental não poderia medir-se apenas pelo bem estar", lembra Sponville (97). A angústia é algo que nos acompanha desde o momento do nascimento até a morte, portanto ela faz parte da vida. É muito angustiante nascer, como é angustiante morrer. Entre um polo e outro transcorre a vida: angustiante e maravilhosa. Seria enganosa a busca de felicidade que negasse essa verdade do existir humano.

A relação amorosa é igualmente angustiante, porque o outro, meu objeto de desejo, é diferente de mim, não me deseja como quero ser desejado, não se envolve na medida do meu sonho, e é capaz de partir e me abandonar a sós com meu desejo. Em lugar do desafio do conviver fica mais fácil consumir "coisas felizes", "pílulas felizes" a enganar o próprio vazio. No entanto é lá, no mais dentro que somos felizes, e infelizes. É aí que nos construímos, que nos inventamos. É nesse mais dentro que será possível aninhar a verdade inevitável do finito que somos, com carinho, com dignidade, sem desespero, com o Narciso na mira de um mais além do próprio espelho. "Não se trata de não sofrer... mas de ser feliz tanto quanto se conseguir, e, nunca se é feliz senão aproximadamente" Sponville (97).

\section{REFERÊNCIAS BIBLIOGRÁFICAS}

1. ANDRÉ, S. O que quer uma mulher? Rio de Janeiro: Jorge Zahar Ed., 1987.

2. CHALHUB, S. Poética do erótico. São Paulo: Escuta, 1993.

3. DEBORD, G. A sociedade do espetáculo. Rio de Janeiro: Contraponto, 1997.

4. McDOUGALL, J. Conferências brasileiras. Rio de Janeiro: Xenon, 1987.

5. PRADO, A. Poesia reunida. São Paulo: Siciliano, 1991.

6. PLATÃO. Diálogos. São Paulo: Cultrix, 1995.

7. SPONVILLE, A. C. Pequeno tratado das grandes virtudes. São Paulo: Martins Fontes, 1996.

8. Bom dia, angústia! São Paulo: Martins Fontes, 1997. 